\title{
Kasus-Kasus Maternal di Berita Online Menyangkut Hak Asasi yang Patut Menjadi Pelajaran dalam Pendidikan Bidan di Indonesia
}

\section{Maternal Cases in Online News with Human Rights Concern that Deserve to be Learned in Midwife Education in Indonesia}

\author{
MV. Virahayu ${ }^{1}$, D. Dasuki², O. Emilia², M. Hasanbasri ${ }^{2}$, dan M. Hakimi ${ }^{2}$ \\ 1) Prodi S1 Kebidanan, STIKes AKBIDYO, Jln Parangtritis km 6, Sewon, Kabupaten Bantul, Daerah Istimewa \\ Yogyakarta 55188, Indonesia \\ 2) Kedokteran dan Kesehatan, Universitas Gadjah Mada, Jln Farmako, Senolowo, Sekip Utara, Mlati, Kabupaten \\ Sleman, Daerah Istimewa Yogyakarta, 55281, Indonesia
}

Korespondensi: virahayuakbidyo@gmail.com

Submitted: 20 September 2018, Revised: 26 November 2018, Accepted: 7 Desember 2018

https://doi.org/10.22435/jpppk.v2i3.813

\begin{abstract}
Abstrak
Gerakan menghormati hak asasi manusia dalam pelayanan kesehatan maternal di berbagai negara mendorong petugas kesehatan bertindak lebih manusiawi. Perempuan selama ini diam karena tidak ingin memutus hubungan harmonis dengan bidan serta jarangnya isu ini diangkat dalam pertemuan profesi dan publikasi ilmiah menyebabkan perhatian yang rendah terhadap hak asasi manusia dalam pelayanan kesehatan maternal. Penelitian ini bertujuan untuk mengidentifikasi kegagalan dalam pemenuhan hak kesehatan ibu hamil dan bersalin serta mengeksplorasi alasan-alasan yang menyebabkan hal tersebut terjadi. Metode penelitian dilakukan dengan melakukan penelusuran berita online kompas.com, tribunnews.com, dan detiknews.com tahun 2016-2018 dengan kata kunci "malpraktik" dan "bidan", tentang persoalan hak asasi manusia dalam pelayanan bidan. Kami mengikuti kasus dalam lebih dari satu media online, disertai perkembangan berita tentang kasus tersebut. Hasil penelitian menunjukkan bahwa dominasi bidan dalam pelayanan kesehatan maternal di Indonesia, berdampak pada pengabaian hak asasi perempuan dan keselamatan. Kejadian ini pada kelompok orang dengan pendapatan rendah dan kelompok yang mampu. Didapatkan praktik bidan di luar kewenangan, kemungkinan motivasi mendapatkan keuntungan, dominasi bidan, posisi sosial perempuan yang rendah dalam pelayanan kesehatan maternal, dan keterlibatan masyarakat yang rendah untuk mendukung perempuan yang mengalami ketidakadilan dalam layanan kesehatan. Kepercayaan dan ketergantungan perempuan pada bidan, berdampak pengabaian hak asasi dan keselamatan ibu, tindakan di luar kewenangan, untuk pencarian keuntungan dalam praktik pribadi. Organisasi profesi dan pendidik bidan harus memasukkan penerapan hak asasi manusia dalam praktik kebidanan melalui kasus-kasus dari berita online dalam pertemuan berkala asosiasi profesi, serta kurikulum pendidikan, untuk mencegah dampak buruk pengabaian hak asasi ibu di masa depan.
\end{abstract}

Kata kunci: pengabaian hak asasi dalam layanan bidan, kasus malpraktik bidan, penguatan pendidikan bidan

\section{Abstract}

The movement to respect human rights in maternal health services in various countries encourages health workers to act more humanely. Low attention to human rights issue in maternal health services due to the silent of the victims-because women do not want to break the harmonious relationship with midwives, and this issue is rarely raised in professional meetings and scientific publications. This study aims to identify failures in fulfilling the health rights of pregnant women and childbirth and explore the reasons for this. The research 
method is done by searching online news kompas.com, tribunnews.com, and detiknews.com in 2016-2018 with the keywords "malpractice" and "midwife", about human rights issues in midwifery services. We followed the case in more than one online media, accompanied by the case progress report. The results of the study show that the dominance of midwives in maternal health services in Indonesia has an impact on neglecting women's human rights and safety. This event is in the group of people with low income and groups who are able. The practice of midwive's out of authority, possible motivations for profit, dominance of midwives, low social position of women in maternal health services, and low community involvement in supporting women who experience inequality in maternal health services. Trust and dependence of women on midwives, impact on neglecting human rights and maternal safety, actions that are beyond authority, for seeking profit in private practice. Midwife professional organizations and educators must incorporate the application of human rights in midwifery practice through cases from online news in periodic meetings of professional associations, as well as educational curricula, to prevent the adverse effects of neglecting maternal rights in the future.

Keywords: neglect of human rights in midwife services, midwife malpractice case, strengthening midwifery education

\section{Pendahuluan}

Angka kematian bayi dan ibu (AKB dan $\mathrm{AKI}$ ) yang masih tinggi dalam 3 dasa warsa terakhir menempatkan profesi bidan menjadi salah satu kebijakan sentral di Indonesia. ${ }^{1,2,3}$ Bidan ditempatkan di seluruh pelosok Indonesia dengan pola kontrak agar mau bekerja di daerah ${ }^{4}$ dan di daerah terpencil. ${ }^{1,5}$ Selain sebagai penolong persalinan normal, peran bidan ada banyak dan bahkan menyangkut pemberian konseling bagi penduduk yang masih ragu untuk berkunjung ke tempat profesional, ${ }^{5,6}$ sehingga bidan dituntut untuk memahami masalah-masalah budaya penduduk setempat agar mau berpartisipasi mengatasi masalah mereka sendiri ${ }^{1}$ dan bagaimana kolaborasi sesama bidan agar ibu hamil memperoleh manfaat maksimal dari program puskesmas. Meskipun demikian, implementasi program bidan di seluruh pelosok Indonesia memiliki tantangan yang tidak sedikit.

Sikap diam demi menjaga harmoni yang menjadi kebiasaan perempuan Asia, menyebabkan isu kekerasan yang dialami dalam pelayanan kesehatan maternal tidak banyak dilaporkan dan dikaji. ${ }^{7}$ Sistem pelayanan kesehatan yang memberi peluang untuk melakukan tindakan diluar kewenangan, adalah godaan bagi ketaatan terhadap etika profesi. Praktik tidak manusiawi oleh bidan dilatarbelakangi pengalaman saat pendidikan, hubungan kolegial serta keinginan untuk menunjukkan jati diri dan eksistensi profesi. ${ }^{8,9,10}$ Penelitian yang dilakukan oleh Hardee $\mathrm{K}$, dkk (2012) menunjukkan praktik tidak manusiawi menyebabkan morbiditas dan mortalitas. ${ }^{11}$ Pengabaian keselamatan pasien, tindakan diluar kewenangan demi kepentingan pribadi, adalah perlakuan tidak manusiawi dalam praktik kebidanan yang sebenarnya selama ini terjadi di Indonesia, namun jarang ditulis.

Perlakuan tidak manusiawi oleh bidan telah menjadi isu global. ${ }^{12}$ Perempuan mengalami perlakuan tidak manusiawi dalam bentuk kekerasan, disrespek, pelecehan, dan tidak diperhatikan kebutuhannya selama bersalin., ${ }^{9,13,14}$ Contoh: di Ghana, perempuan mengalami penelantaran, dan diskriminasi selama persalinan. ${ }^{15}$ Tindakan kasar dan mengancam, dilakukan oleh bidan terhadap perempuan bersalin di rumah sakit negara Swedia. ${ }^{16}$ Stereotyping dilakukan bidan di negara maju terhadap klien yang berasal dari negara berkembang atau etnis minoritas. ${ }^{8,17,18,19,20,21}$ Tidak ada dukungan emosional dan informasi bagi ibu nifas yang mengalami stillbirth di Indonesia, adalah tindakan pengabaian, menyebabkan beban psikologis jangka panjang yang tidak disadari oleh bidan..$^{22}$ Pelayanan persalinan dengan kekerasan yang dilakukan oleh bidan menyebabkan perempuan hamil tidak memanfaatkan fasilitas kesehatan maternal. ${ }^{23}$ Upaya meningkatkan kualitas kesehatan maternal dan pelayanan profesional menjadi terkendala perilaku kekerasan oleh bidan.

Artikel ini ingin menunjukkan terjadi praktik tidak manusiawi terhadap pasien oleh bidan di Indonesia. Kami menyajikan uraian tentang pentingnya memahami setiap fenomena yang terjadi dibalik kasus malpraktik. Kami menggunakan ilustrasi 3 kasus yang menjadi perhatian publik, diterbitkan dalam koran online untuk menjelaskan kedalaman kekerasan oleh bidan bagi 
pasien. Bagian akhir tulisan ini, kami mendiskusikan strategi untuk memperbaiki pelayanan bidan agar kekerasan tidak terjadi, yang mencakup continuing education tentang hak asasi dan kemanusiaan oleh organisasi profesi.

\section{Tujuan}

Penelitian ini mencoba mengungkap kejadian tidak manusiawi dan mengidentifikasi kegagalan pemenuhan hak kesehatan ibu dengan mengambil informasi yang bersumber dari media online dan mengeksplorasi alasan-alasan yang menyebabkan hal tersebut terjadi.

\section{Metode}

Metode penelitian dengan menggunakan analisis konten, untuk menunjukkan pelanggaran hak asasi yang dilakukan oleh bidan dalam praktik. Analisis konten terhadap narasi atau berita tentang pelayanan kesehatan, dapat mengungkapkan fenomena yang terjadi di balik morbiditas, mortalitas, dan apa yang dianggap penting oleh pasien. Penelitian ini merupakan upaya untuk mengungkapkan kejadian tidak manusiawi oleh bidan yang merugikan klien. Data untuk studi ini diambil dari kasus yang sudah menjadi perhatian publik di media online. Media yang digunakan dalam studi ini adalah Kompas.com, Tribunnews.com, dan Detiknews.com. Berita yang diamati mencakup kurun waktu tahun 2016 sampai 2018. Kasus ditelusuri dengan kata kunci: kasus malpraktik bidan. Berita tentang kasus malpraktik yang diperoleh, dianggap benarjika terdapat lebih dari satu koran online memberitakan dan terdapat informasi perkembangan kasus tersebut. Isu-isu pokok dalam berita tersebut ditampilkan, untuk mengetahui latar belakang pelanggaran hak asasi yang terjadi. Kasus-kasus publik ini digunakan karena data yang diduga menyangkut malpraktik tersimpan dalam dokumen audit di dinas kesehatan, yang tidak bisa diakses untuk penelitian seperti ini. Kami bahkan memulai studi bibliometrik yang mencari riset terkait malpraktik oleh bidan yang ditulis dalam jurnal kebidanan Indonesia terakreditasi Dikti. Penelusuran artikel dimulai dengan identifikasi menggunakan kata kunci "bidan" dan "malpraktik" serta "bidan" dan "praktik kekerasan". Sumber informasi adalah 3 jurnal bidan Indonesia yang telah terakreditasi Dikti, yaitu e-journal.ibi.or.id, thejmch.com, dan mji.ui.ac.id selama kurun waktu 2016 sampai 2018. Tidak ada satu penelitian yang ditemukan atas dasar strategi itu. Penting dicatat bahwa dalam "content analysis", peneliti bersandar pada apa yang ditulis dalam media. Meskipun ketidakmungkinan verifikasi data merupakan salah satu kelemahan Validitas informasi dijaga dengan melakukan triangulasi sumber melalui informasi yang sama dari media yang lain. (Gambar 1)

\section{Hasil}

\section{Kasus Maternal yang Menjadi Sorotan Media Publik}

Ketiga kasus ini menonjol dalam hal praktik tidak manusiawi. Praktik bidan ini menyebabkan mortalitas dan morbiditas, tetapi di Indonesia hal tersebut tidak banyak dituliskan dalam artikel ilmiah. Perlakuan tidak manusiawi oleh bidan, didapatkan melalui pemberitaan di televisi, koran atau media

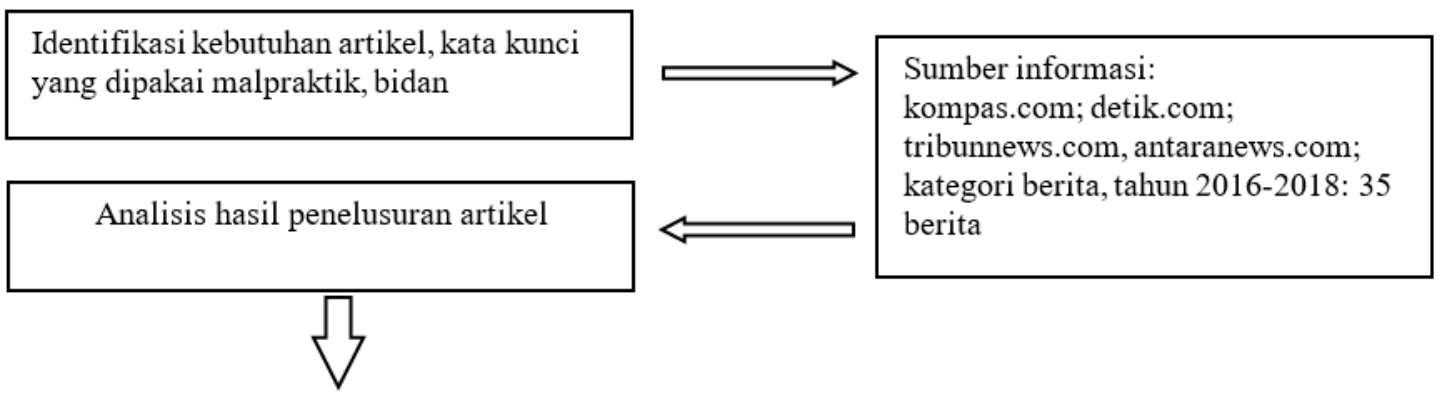

Hasil akhir penelusuran artikel: 3 berita yang sesuai

\section{Gambar 1. Alur Penelusuran Artikel}


online. Penelusuran menghasilkan 3 berita di media online, yang menjadi perhatian publik. Berikut adalah ringkasan kasus.

\section{Kasus 1: Aborsi di Luar Kewenangan dan Motif Keuangan}

Bidan DSB dan NN alias Na, ibu muda yang sedang hamil 5 bulan, menjadi tersangka dalam kasus aborsi. NN melakukan aborsi di klinik bersalin milik DSB. Berdasarkan pengakuan NN, aborsi dilakukan karena janin yang dikandungnya tidak berkembang dan denyutnya tidak terekam. $\mathrm{NN}$ datang ke klinik bidan bersama ibunya, pada tanggal 17 Januari 2016. Bidan DSB melakukan pemeriksaan dan menyimpulkan bahwa janin dalam kandungan $\mathrm{NN}$ harus dikeluarkan karena sudah mati. NN diberi obat untuk menggugurkan kandungannya, dan harus membayar biaya tindakan aborsi dan perawatan sebesar 10 juta rupiah. Kasus aborsi di klinik bidan DSB, diketahui pihak kepolisian akibat laporan warga setempat yang mencurigai perubahan fisik NN. Hasil penyelidikan polisi menunjukkan kecurigaan bahwa klinik tersebut tidak memiliki ijin dari dinas kesehatan setempat. Bidan DSB memiliki dua klinik di wilayah tersebut. Berdasarkan keterangan saksi, praktik aborsi sering dilakukan di Bonipoi," kata Didik, Senin (25/1/2016). Namun, menurut Didik, setelah pihaknya mendapati dua kuburan janin di klinik milik bidan DSB di Pasir Panjang, maka tidak tertutup kemungkinan klinik ini juga dijadikan tempat aborsi.

Kasus 1 bersumber pada: Merdeka.com, Jumat, 22 Januari 2016 20:23 Reporter: Ananias Petrus; TRIBUNNEWS.COM, Senin 25 Januari 2016 dan Kamis, 4 Februari 2016 19:57 WIB, penulis: Dion Kota, editor: Eko Sutriyanto; Kompas. com - 28/09/2016, 10:34 WIB Kontributor Kupang, Sigiranus Marutho Bere; Liputan6.com, 23 Feb 2017, 14:31 WIB, Ola Keda; timor express/fri/jpnn, Sabtu, 23 Januari 2016 - 09:43 WIB; mediantt.com; che, Januari 2016)

$\mathrm{NN}$ dan keluarga menunjukkan kepercayaan terhadap pelayanan bidan, sehingga melakukan pengambilan keputusan tanpa mengutamakan isu keselamatan. Bidan DSB mengabaikan keselamatan klien dan melakukan tindakan diluar kewenangan, demi keuntungan pribadi. Kepercayaan ibu mendorong bidan melakukan tindakan diluar kewenangan dan mendapatkan keuntungan pribadi.

Masyarakat telah mengetahui bahwa aborsi adalah tindakan ilegal. Kecurigaan masyarakat menyebabkan kasus ini terbongkar ke ranah publik. Keberanian masyarakat menyuarakan pengabaian keselamatan ibu oleh bidan, terjadi karena aborsi telah dipahami sebagai tindakan melawan hukum.

....Praktik aborsi itu, lanjut Didik, terbongkar setelah polisi mendapatkan informasi dari masyarakat yang curiga akan perut $\mathrm{N}$ yang tiba-tiba mengecil... (http://www.tribunnews.com/regional/2016/01/25/ dua-klinik-bidan-di-kupang-diduga-jadi-tempatpraktik-aborsi.)

Masyarakat tidak semua memahami batas kewenangan dan etika profesi bidan. Kecurigaan telah terjadi pelanggaran hukum, menyebabkan kasus ini dilaporkan ke polisi.

"Ada dua tempat praktik milik bidan DSB yang memiliki izin yakni di Kelurahan Pasir Panjang, sedangkan di Kelurahan Bonipoi itu tidak memiliki izin....

(http://www.tribunnews.com/regional/2016/01/25/ dua-klinik-bidan-di-kupang-diduga-jadi-tempatpraktik-aborsi.)

Sesuai informasi yang diperoleh Timor Express (Grup JPNN) di Mapolres Kupang Kota, klinik bersalin milik bidan DSB itu ilegal karena tidak memiliki izin resmi dari dinas terkait... (timor express/fri/jpnn)

Kasus 2: R, seorang perempuan tuna wicara, datang untuk memeriksakan kehamilan di Puskesmas rawat jalan Kecamatan Sungai Kunyit, Mempawah Hilir. R didampingi keluarganya, karena suami bekerja di Malaysia sejak hampir setahun yang lalu. Kehamilan ketiga ini sangat diharapkan, karena kedua anak dari kehamilan sebelumnya, meninggal. Puskesmas tersebut tidak melayani rawat inap dan persalinan. Pelayanan kebidanan dan kandungan hanya sebatas pemeriksaan kehamilan. Dokter puskesmas melakukan pemeriksaan USG terhadap R. Hasil pemeriksaan menunjukkan indikasi rujukan kasus ke RSUD dr Rubini untuk perawatan lebih lanjut. Dokter curiga terdapat kondisi abnormal pada kehamilan R. Usia kehamilan R saat itu adalah 38 minggu. Keluarga R, memutuskan untuk mengikuti anjuran dokter. Nu-orang tua $\mathrm{R}$, menyatakan akan mengurus BPJS terlebih dahulu, 
karena tidak memiliki biaya untuk berobat ke rumah sakit. Rencana $\mathrm{Nu}$ untuk mengurus BPJS dan membawa $\mathrm{R}$ ke rumah sakit di kota, diketahui oleh bidan TD-kepala Puskesmas Sungai Kunyit. Bidan tersebut menawarkan agar $\mathrm{R}$ dibawa ke klinik bersalin miliknya. Pertimbangannya adalah kedekatan dengan keluarga dan kemudahan urusan administrasi. $\mathrm{N}$ tidak perlu mengurus BPJS dan mengeluarkan biaya transportasi untuk membawa $\mathrm{R}$ ke rumah sakit di kota. Keluarga juga tidak perlu memikirkan biaya hidup selama menunggui $\mathrm{R}$ di kota. Biaya persalinan di klinik milik bidan TD hanya Rp 900.000,- sudah termasuk penjemputan Rina dari rumah ke klinik dan administrasi untuk pembuatan akta kelahiran. $\mathrm{N}$ menerima tawaran bidan TD. R dijemput untuk dirawat di klinik bidan TD pada pukul 01.00 WITA tanggal 21 Juli 2016. Proses persalinan $\mathrm{R}$ ternyata mengalami kesulitan. Bidan TD memutuskan melakukan ekstraksi vakum, agar bayi dapat segera dilahirkan. $\mathrm{N}$ menceritakan bahwa proses ekstraksi vakum tidak mudah. Alat tersebut lepas sebanyak empat kali, dan bayi tetap tidak lahir. R akhirnya dirujuk ke Rumah Sakit dr Rubini. Dokter di rumah sakit tersebut tidak dapat melakukan tindakan medis, sehingga memutuskan untuk merujuk R ke RSUD dr Abdul Aziz Singkawang. R-dalam keadaan kesakitan, menempuh perjalanan jauh menuju Singkawang. Tim medis di RSUD dr Abdul Aziz Singkawang akhirnya berhasil melahirkan bayi tersebut, dalam kondisi sudah tidak bernyawa. Bayi meninggal dalam kandungan, diduga akibat trauma persalinan. $\mathrm{R}$ harus merelakan kehilangan anak untuk ketiga kalinya.

Berdasarkan informasi dari pihak dinas kesehatan, diduga terjadi pelanggaran prosedur pelayanan bidan dan izin praktik. Wakil ketua Ikatan Bidan Indonesia setempat telah melaporkan kasus dugaan malpraktik yang dilakukan bidan TD ke dinas kesehatan. Data dari Ikatan Bidan Indonesia menunjukkan bidan TD telah melakukan malpraktik lebih dari satu kali.

Kasus 2 bersumber pada: Suara Pemred; Editor sutan 2016-07-27 12:33:04 pm; thetanjungpuratimes.com: 27 Juli 2016; Hamzah/ Dd; 26 Juli 2016 17:54: TRIBUN PONTIANAK. CO.ID, Penulis: Dhita Mutiasari; Editor: Steven Greatness; thetanjungpuratimes.com: 3 Agustus
2016; Hamzah/dd; MEMPAWAH,SP: ben/bah/sut. Kasus ini menonjol dalam hal pengabaian keselamatan klien, dominasi bidan terhadap profesi lain, dan pertimbangan finansial dalam sebuah keluarga miskin.

Keluarga $\mathrm{R}$ percaya terhadap kemampuan klinis dan pertimbangan rasional yang disarankan bidan. Kondisi sosial menyebabkan pertimbangan ekonomi diutamakan dibandingkan keselamatan ibu.

..Seperti diberitakan sebelumnya, $R$ (32) adalah ibu muda tuna wicara. Dia sudah dua kali mengandung, namun anaknya meninggal saat masih kecil dan dalam kandungan...(Suara Pemred: IBI Mempawah Laporkan Dugaan Malpraktik ke Diskes)

R diduga menjadi korban malpraktik saatmelahirkan anaknya yang ketiga. Sementara suaminya saat ini bekerja di Malaysia sudah hampir setahun..... (http://pontianak.tribunnews.com: Breaking news: detik-rina-akan-melahirkan-dan-ditangani-bidan) Alasan Nu ingin mengurus BPJS karena tidak memiliki biaya persalinan di rumah sakit. Dan pilihan mendaftar ke BPJS, biaya bisa gratis... Namun dalam obrolan itu, bidan TD malah mengajak Nu ke kliniknya dengan iming-iming dan gak usah pakai BPJS. "Katanya kalau gunakan BPJS terburu terlambat," kata Nu, menirukan percakapan TD.. (Suara Pemred:Bidan Klinik Mempawah Hilir Diduga Malpraktik)

Pengabaian keselamatan $\mathrm{R}$ dilakukan oleh bidan dan keluarga sendiri. Bidan memanfaatkan kepercayaan dan ketidaktahuan pasien untuk keuntungan pribadi. Keluarga memutuskan mengikuti saran bidan, karena ada solusi lain yang lebih ekonomis dan praktis.

"Jadi, bagusan di klinik saya saja, kata bu TD. Karena saya mempunyai dua klinik. Satu di Mempawah dan di Sui Pinyuh. Dan nantinya saat penjempuatan dan bikin akta dan kelahiran hanya sekitar Rp.900 ribu," Nu kembali menirukan percakapan TD....(Suara Pemred: Bidan Klinik Mempawah Hilir Diduga Malapraktek)

Kepercayaan ibu dan keluarga terhadap bidan menyebabkan saran untuk dirujuk ke pelayanan spesialis, diabaikan. Kasus ini menunjukkan peran bidan yang dominan atas pengambilan keputusan dalam pelayanan kesehatan maternal. 
"Jadi, kata pihak Puskesmas harus dibawa ke rumah sakit Dr Rubini. Namun Kepala Puskesmas justru menawari agar anaknya dibawa ke kliniknya di Mempawah....(thetanjungpuratimes.com:Oknum Bidan di Mempawah Diduga Melakukan Tindakan Malpraktik)

Pelanggaran aturan dan etika profesi oleh bidan TD dilakukan lebih dari 1 kali. Bidan TD diketahui memiliki 2 buah klinik bersalin. Kedua klinik tersebut masih beroperasi dan isu legalitas dipersoalkan setelah kasus R terungkap ke publik.

..klinik persalinan kebidanan juga dikatakannya tak memperbolehkan memiliki dua klinik.. (Suara Pemred: Bidan Klinik Mempawah Hilir Diduga Malpraktik)

.... Dikatakannya, kasus dugaan malpraktik yang dilakukan oleh oknum bidan tersebut, bukan baru pertama kali terjadi di Mempawah. Berdasarkan data yang dimiliki IBI Mempawah setidaknya ada sejumlah dugaan malpraktik yang dilakukan sang bidan. ....(thetanjungpuratimes.com:Terkait Oknum Bidan Diduga Malpraktik, IBI Mempawah Layangkan Surat ke Dinkes)

"Menurut data-data yang ada, dugaan malpraktik yang dilakukan bidan TD sudah lebih dari sekali," ungkapnya. ...(Suara Pemred: IBI Mempawah Laporkan Dugaan Malpraktik ke Diskes)

Kasus 2 membuktikan bahwa diperlukan perhatian terhadap isu sosial dan kemanusiaan, dalam praktik bidan sehari-hari.

\section{Kasus 3: berharap besar terhadap pertolongan bidan, tetapi tidak terjadi}

Sa dan Sae adalah suami istri, penduduk Kampung Cikotak, Desa Cibeureum, Kabupaten Serang, Banten. Keluarga tersebut tinggal di perbukitan Padarincang. Sae sedang hamil anak keempat, merasakan tanda-tanda akan melahirkan pada tanggal 15 Juni 2018 pukul 23.00 WIB. Esok hari, adalah Hari Raya Idul Fitri. Sae tidak dibawa ke bidan atau ke puskesmas terdekat ketika tandatanda persalinan awal mulai dirasakan. Satu jam kemudian, Sae melahirkan. Kelahiran tersebut membuat Sa panik, sehingga memanggil paraji (dukun beranak) untuk menolong istri dan bayi yang baru dilahirkannya. Sae mengalami perdarahan. Paraji meminta Sa mendatangkan bidan desa, untuk membantu menghentikan perdarahan yang dialami Sae. Dukun beranak tersebut tidak mampu mengatasi masalah yang terjadi.

Sa segera pergi ke bidan terdekat. Sa pergi tanpa membawa serta Sae. Kondisi geografis tempat tinggal Sae, menjadi hambatan untuk datang ke bidan atau puskesmas terdekat. Kondisi Sae yang masih sadar, menyebabkan semua orang di rumah tersebut yakin bahwa keadaan akan baik-baik saja.

Bidan terdekat yang bisa didatangi oleh $\mathrm{Sa}$ adalah US. Perempuan tersebut menerima kedatangan Sa pada tanggal 16 Juni 2018 pukul 01.30 WIB. US adalah bidan Puskesmas Padarincang, yang membuka praktek mandiri di rumahnya, di desa Padarincang. US bukan bidan desa setempat, karena pertimbangan profesi dan jarak, maka sangat masuk akal Sa minta pertolongan kepadanya. Kedatangan suami Sae dini hari, bermaksud mengajak bidan US datang ke rumahnya menolong Sae yang mengalami perdarahan. Maksud dan tujuan kedatangan Sa, segera dipahami dengan baik oleh bidan US. Keinginan Sa untuk mengajak bidan US ke rumahnya, tidak berhasil. Bidan US memutuskan untuk tidak mendatangi Sae-ibu yang mengalami perdarahan pasca salin. Alasan yang diberikan adalah: kasus perdarahan yang terjadi (berdasarkan cerita $\mathrm{Sa}$ ) memerlukan penatalaksanaan oleh dokter ahli. US menyarankan agar Sae dibawa ke puskesmas di Cacaban.

Sa mengikuti saran US, untuk mencari pertolongan ke Puskesmas Padarincang. Menurut pengakuan Sa, tidak ada seorang petugas pun yang piket pada dini hari lebaran tersebut. Sa kemudian pulang ke rumahnya. Sa pulang tanpa disertai bidan yang diharapkan dapat menolong istrinya. Kondisi Saenah semakin memburuk, dan akhirnya Sae meninggal dunia. Tiga jam lamanya Sae bertahan dalam kondisi perdarahan, tanpa mendapatkan pertolongan profesional.

Proses kematian Sae menjadi bahan pembicaraan oleh warga. Wartawan koran online datang, mengunjungi Sa kemudian menuliskan kisah tersebut. Bidan US dan pihak Puskesmas Padarincang merasa perlu melakukan klarifikasi terhadap informasi yang beredar. Satu hari setelah berita kematian Sae tayang di koran online, Bidan US menulis surat terbuka sebagai klarifikasi peristiwa tersebut. Para petugas Puskesmas Padarincangselaku penanggungjawab pelayanan kesehatan 
dasar di wilayah tersebut, mengunjungi Sa untuk menjelaskan bahwa kematian Sae seharusnya tidak terjadi jika ibu tersebut bersalin di fasilitas kesehatan.

Kasus 3 bersumber pada: detikNews, Senin 25 Juni 2018, 12:09 WIB; Reza Gunadha, Suara. com;Senin, 25 Juni 2018 | 20:12 WIB;BantenNews. co.id- Senin, 25 Juni 2018 | 15:02;BantenNews. co.id -Selasa, 26 Juni 2018 | 14:05

Kasus ini sangat kental dengan tindakan tidak manusiawi. Ketidakhadiran bidan ketika Sae mengalami perdarahan pasca salin adalah tindakan tidak manusiawi.

"Bu, saya minta tolong, istri saya sudah melahirkan, bayi sudah di luar, keadaan kritis. Ibu mau saya bawa ke rumah. Kata dia nggak bisa. Alasannya nggak pernah dipanggil, nggak pernah dibawa (ke warga). Itu mah bawa saja ke Cacaban (puskesmas). Di sana peralatannya cukup. Dokter ada," kata Sa ...(BantenNews.co.id: Tak Dapat Pelayanan Medis, Ibu Hamil Asal Padarincang Meninggal pada Malam Lebaran)

US, bidan di Desa Padarincang membantah menolak memberi pelayanan kepada Sae, ibu hamil asal Desa Cibeureum,...Melalui surat yang dikirimkan ke BantenNews.co.id, US menyampaikan saat itu kondisi yang disampaikan oleh Sa (suami Sae) adalah kasus patologis yang harus ditangani dokter ahli.. ...(BantenNews.co.id: Bidan di Padarincang Bantah Tolak Ibu Hamil Hingga Meninggal)

Sae mengalami persalinan dan perdarahan pasca salin tanpa mendapatkan pertolongan profesional.

Sa bercerita, pada Jumat (15/6) pukul 23.00 WIB, istrinya mengalami kontraksi. Sejam kemudian bayinya langsung keluar. Ia panik mencari dukun beranak. Begitu tiba, si dukun rupanya tidak sanggup dan menyarankan minta pertolongan bidan karena sudah terjadi pendarahan..

(-detikNews: Pilu Warga Banten Kehilangan Istri yang Melahirkan di Malam Lebaran)

"Itu mah bawa saja ke Cacaban (puskesmas). Di sana peralatannya cukup. Dokter ada," kata Sa ... (BantenNews.co.id: Tak Dapat Pelayanan Medis, Ibu Hamil Asal Padarincang Meninggal pada Malam Lebaran)

\section{Temuan Tema Kemanusiaan dari Analisis terhadap Tiga Kasus}

Isu utama dalam ketiga berita tersebut, dapat dilihat pada Tabel 1. Berita tentang NN, R dan Sae, adalah gambaran kecil dari sejumlah besar kasus morbiditas serta mortalitas yang terjadi di Indonesia. Bidan DS, TD, dan US adalah pemilik klinik bersalin. Bidan TD adalah kepala Puskesmas Sungai Kunyit, sedangkan bidan US adalah petugas Puskesmas Padarincang. Tiga kasus perlakuan tidak manusiawi oleh bidan. (Tabel 1)

Tabel 1 menunjukkan, pengabaian keselamatan ibu menjadi latar belakang morbiditas dan mortalitas pada ketiga kasus. Pengambilan keputusan tanpa memperhatikan keselamatan ibu menjadi hambatan pemenuhan hak asasi manusia. Kepercayaan masyarakat terhadap bidan untuk masalah kehamilan dan persalinan, menunjukkan peran spesifik profesi tersebut. Bidan, sebagai profesi pelayanan kesehatan maternal yang terdekat dengan masyarakat, menjadi lebih dipercaya daripada profesi lain.

\section{Kepercayaan terhadap Bidan}

Bidan sebagai tenaga kesehatan dengan kemampuan spesifik dan dekat dengan masyarakat karena berada di desa dan di kecamatan, telah berhasil disosialisasikan selama hampir 30 tahun. Program bidan desa telah menggeser para pelaku pelayanan kebidanan tradisional, menggantikan dengan praktik kebidanan ilmiah yang aktual. Keberhasilan yang ditunjukkan bidan, menimbulkan kepercayaan bahwa profesi ini mampu menyelesaikan semua masalah kebidanan yang terjadi. Kepercayaan masyarakat terhadap bidan, dapat menimbulkan risiko penyalahgunaan, sehingga terjadi tindakan diluar kewenangan, atas kesepakatan bersama.

Sesuai pengakuan dua orang pegawai bidan DS, jelas Didik, NN datang ke klinik bersalin milik bidan DS di Bonipoi dan mengeluh tentang kehamilanya... (Merdeka.com:Bidan di Kupang layani aborsi, tempat praktik jadi kuburan orok)

...Namun dalam obrolan itu, bidan TD malah mengajak Nu ke kliniknya dengan iming-iming dan gak usah pakai BPJS. "Katanya kalau gunakan BPJS terburu terlambat," kata Nu, menirukan percakapan TD.. (Suara Pemred:Bidan Klinik Mempawah Hilir Diduga Malpraktik) 


\section{Tabel 1. Tema Utama dalam Kasus}

\begin{tabular}{|c|c|c|c|}
\hline Isu Utama dalam Kasus & Kasus 1 & Kasus 2 & Kasus 3 \\
\hline $\begin{array}{l}\text { Kepercayaan terhadap } \\
\text { bidan }\end{array}$ & $\begin{array}{l}\text { Pergi meminta pertolongan } \\
\text { bidan karena tahu } \\
\text { kehamilan bermasalah } \\
\text { Berani membayar mahal } \\
\text { untuk aborsi yang } \\
\text { ditawarkan }\end{array}$ & $\begin{array}{l}\text { Dokter bahkan meminta } \\
\text { dirujuk rumah sakit, tetapi } \\
\text { yang bersangkutan memilih } \\
\text { mengikuti saran bidan }\end{array}$ & $\begin{array}{l}\text { Percaya jika bidan akan } \\
\text { datang dan membantu, } \\
\text { setelah dukun tidak sanggup } \\
\text { mengatasi masalah. }\end{array}$ \\
\hline $\begin{array}{l}\text { Pengabaian keselamatan } \\
\text { ibu }\end{array}$ & $\begin{array}{l}\text { Memulangkan ibu setelah } \\
\text { diberi obat pemacuan } \\
\text { persalinan }\end{array}$ & $\begin{array}{l}\text { Meminta untuk dirawat di } \\
\text { klinik bersalin meskipun } \\
\text { kondisi ibu seharusnya } \\
\text { dirujuk ke rumah sakit }\end{array}$ & $\begin{array}{l}\text { Mampu menolong tetapi } \\
\text { justru tidak mau datang untuk } \\
\text { menolong, meminta keluarga } \\
\text { untuk mencari pertolongan } \\
\text { ke puskesmas }(*)\end{array}$ \\
\hline $\begin{array}{l}\text { Tindakan di luar } \\
\text { kewenangan }\end{array}$ & Aborsi & $\begin{array}{l}\text { Vakum ekstraksi, pemberian } \\
\text { obat pemacu persalinan }\end{array}$ & $\begin{array}{l}\text { Terbalik, memiliki } \\
\text { kewenangan tetapi justru } \\
\text { tidak berusaha membantu }\end{array}$ \\
\hline Keuntungan pribadi & $\begin{array}{l}\text { Menganjurkan pengguguran } \\
\text { dengan biaya } 10 \text { juta rupiah. }\end{array}$ & $\begin{array}{l}\text { Menjanjikan fasilitas dan } \\
\text { kemudahan dibandingkan } \\
\text { jika mengurus bpjs }\end{array}$ & $\begin{array}{l}\text { Mencari aman untuk diri } \\
\text { bidan }\end{array}$ \\
\hline Vulnerabilitas & $\begin{array}{l}\text { Relatif mampu membayar, } \\
\text { status sosial tidak dijelaskan }\end{array}$ & $\begin{array}{l}\text { Pasien dari keluarga } \\
\text { sederhana yang tinggal di } \\
\text { desa, status sosial rendah }\end{array}$ & $\begin{array}{l}\text { Pasien berasal dari keluarga } \\
\text { buruh tani yang tinggal di } \\
\text { perbukitan desa, status sosial } \\
\text { rendah }\end{array}$ \\
\hline
\end{tabular}

(*) Perdarahan pasca salin menyebabkan kondisi mengancam nyawa. Setiap bidan sebagai penolong persalinan telah memiliki kemampuan melakukan stabilisasi pada kasus perdarahan.

Begitu tiba, si dukun rupanya tidak sanggup dan menyarankan minta pertolongan bidan karena sudah terjadi pendarahan..

(-detikNews: Pilu Warga Banten Kehilangan Istri yang Melahirkan di Malam Lebaran)

Masyarakat mungkin tidak mengetahui secara jelas risiko yang akan terjadi. Ketiga kasus menunjukkan ada kepercayaan terhadap bidan. Kasus 1, klien percaya bahwa bidan mampu melakukan tindakan aborsi; pada kasus 2 klien lebih percaya terhadap argumen yang diajukan bidan dibandingkan dokter atau petugas puskesmas yang lain. Bidan TD (kasus 2) memberikan alternatif solusi yang rasional bagi kondisi sosial dan keuangan klien. Kasus 3, menunjukkan ada kepercayaan dukun dan suami klien terhadap kemampuan serta kemauan bidan untuk mengatasi perdarahan setelah melahirkan. Dukun dan suami klien yakin bahwa dalam kondisi perdarahan, bidan akan datang untuk memberikan pertolongan. Dukun dan suami klien tidak memahami risiko yang mungkin terjadi, sehingga tidak langsung mencari pertolongan ke puskesmas terdekat saat persalinan dimulai. Kepercayaan terhadap bidan, bukan isu yang menyingung rasa kemanusiaan. Sikap percaya dapat memicu terjadi tindakan diluar kewenangan yang menyebabkan persoalan kemanusiaan.

\section{Perlakuan Tidak Manusiawi terhadap Pasien oleh Bidan dan Pengabaian Keselamatan}

Ketiga kasus menunjukkan pengabaian keselamatan ibu dalam pengambilan keputusan. Pengabaian keselamatan dalam ketiga kasus, dilakukan oleh bidan terhadap klien. Isu ini memiliki efek kemanusiaan yang paling berat dibandingkan tindakan diluar kewenangan dan keuntungan pribadi. Kasus 1 dan 2 menunjukkan bahwa bidan berani mengambil risiko melakukan suatu tindakan yang membahayakan klien. Kasus 3 menunjukkan hal sebaliknya. Bidan pada kasus 3, memilih untuk membiarkan klien dalam keadaan perdarahan karena merasa kasus tersebut lebih sesuai ditatalaksana oleh dokter ahli. 


\section{Tindakan di Luar Kewenangan}

Ada 2 kasus tindakan diluar kewenangan oleh bidan terhadap klien. Tindakan diluar kewenangan menjadi isu yang menyentuh sisi kemanusiaan, jika ada unsur kesengajaan tanpa kondisi kedaruratan dan keuntungan pribadi. Undang-undang kesehatan telah memberikan peluang bagi bidan untuk melakukan tindakan diluar kewenangan, ketika tidak ada tenaga kesehatan lain yang mampu melakukan tindakan tersebut. Landasan hukum ini tampaknya berpeluang disalahgunakan ketika klien mengalami kendala geografis, jarak, kemampuan finansial, fasilitas, dan kondisi sosialsebagaimana yang terjadi pada kasus 2 .

Seorang bidan di Kota Kupang, Nusa Tenggara Timur (NTT) berinisial DSB, ditangkap aparat Kepolisian Resor Kupang Kota, lantaran terlibat kasus aborsi terhadap $N N$ alias $N$ (23).

h t tp s: //regional.kompas.com / read/2016/01/23/04231081/Terlibat.Kasus.Aborsi.

Seorang.Bidan.di.Kupang.Ditangkap.

Agar bayi bisa lahir dari rahim, TD kemudian memberikan perangsang untuk melahirkan dan anaknya agar cepat keluar. TD kemudian mengambil fakum untuk menyedot bayi dari rahim

(Suara Pemred:Bidan Klinik Mempawah Hilir Diduga Malpraktek)

\section{Keuntungan Pribadi}

Tindakan di luar kewenangan untuk keuntungan pribadi, tampaknya menjadi modus utama bidan pada kasus 1 dan 2 . Hal tersebut dapat dilihat dari kutipan kesaksian dan dialog antara klien dengan bidan.

Dalam kasus ini, polisi juga sudah meminta keterangan dari $N N$ alias $N$ (23) yang meminta bantuan bidan DSB lakukan aborsi janin di dalam kandungannya yang berusia lima bulan dengan tarif Rp 10 juta.....

(http://www.tribunnews.com/regional/2016/01/25/ dua-klinik-bidan-di-kupang-diduga-jadi-tempatpraktik-aborsi.)

..NN alias $N$, untuk menggugurkan janin yang dikandungnya itu, dirinya membayar $R p 10$ juta. Namun, uang muka yang sudah diserahkan ke bidan DSB baru Rp 5 juta. ... (timor express/fri/jpnn)

\section{Vulnarabilitas Pasien}

Klien pada kasus 2 dan 3 berasal dari keluarga miskin. Isu kerentanan sosial sangat menonjol pada kasus 2. Klien adalah seorang perempuan tuna wicara, berasal dari keluarga tidak mampu, dan memiliki riwayat kehamilan yang buruk. Terdapat risiko sosial dan kesehatan pada klien tersebut. Keterbatasan fisik menyebabkan klien perlu didampingi oleh keluarga dalam kasus ini orang tua, untuk membuat pengambilan keputusan atas dirinya, tidak didasarkan pada riwayat kehamilan yang buruk, pertimbangan ekonomi menjadi alasan utama untuk memilih pelayanan yang ditawarkan bidan. Kasus 3 menunjukkan klien berasal dari keluarga miskin yang tinggal di daerah perbukitan. Kemiskinan dan keterpencilan erat kaitannya dengan maternal health literacy yang rendah dan isu kemanusiaan.

Seperti diberitakan sebelumnya, $R$ (32) adalah ibu muda tuna wicara. Dia sudah dua kali mengandung, namun anaknya meninggal saat masih kecil dan dalam kandungan...

(Suara Pemred: IBI Mempawah Laporkan Dugaan Malapraktik ke Diskes)

Alasan Nu ingin mengurus BPJS karena tidak memiliki biaya persalinan di rumah sakit. Dan pilihan mendaftar ke BPJS, biaya bisa gratis...

(Suara Pemred:Bidan Klinik Mempawah Hilir Diduga Malapraktek)

Sa akhirnya kembali ke rumahnya di Cikotak yang lokasinya di perbukitan Padarincang... (BantenNews.co.id: Tak Dapat Pelayanan Medis, Ibu Hamil Asal Padarincang Meninggal pada Malam Lebaran)

"Istilahnya nyalahin saya (karena) nggak dibawa ke sana. Sebelum sakit maksudnya, kenapa nggak dibawa. Di kampung adanya dukun, " ujar Sa, yang sehari-hari bekerja jadi buruh tani.. (detikNews: Pilu Warga Banten Kehilangan Istri yang Melahirkan di Malam Lebaran)

\section{Kepedulian Masyarakat}

Kepedulian masyarakat terhadap perempuan, mempengaruhi kualitas kehidupan mereka. Keengganan perempuan menyuarakan perlakuan yang mereka terima ketika berurusan dengan tenaga kesehatan, menyebabkan kasus- 
kasus kemanusiaan tidak terungkap dan terjadi berulang dengan pola yang serupa. Ketiga kasus menunjukkan masyarakat dan keluarga berani menyuarakan persoalan yang mereka hadapi dalam pelayanan kesehatan maternal. Kasus ini membuktikan, masyarakat perlu diberi pemahaman yang tepat tentang masalah kesehatan maternal yang terjadi sehingga dapat menjadi agent yang menyuarakan kepentingan pelayanan manusiawi bagi perempuan. Kasus pertama terungkap ke publik karena masyarakat mencurigai terjadi praktik ilegal, yaitu aborsi. Kasus kedua diketahui publik akibat cerita disampaikan keluarga kepada wartawan. Keluarga menyuarakan keluhan karena terjadi kematian dan kerugian materi. Kasus ketiga diceritakan oleh keluarga kepada wartawan. Keluarga merasa kecewa karena tidak berhasil mendatangkan bidan yang dipercaya dapat memberi solusi terhadap kasus perdarahan pasca salin. Kekecewaan tersebut bertambah, karena keluarga merasa disalahkan oleh pihak petugas kesehatan. Pemanfaatan dukun dalam kasus persalinan Sae, menimbulkan persoalan baru tentang keterkaitan masyarakat dengan praktik-praktik tradisional secara emosional, yang menjadikan dukun sebagai pengganti bidan jika kehamilan dan persalinan dianggap tidak bermasalah. Kekecewaan terhadap pelayanan bidan yang tampak dalam kasus 2 dan 3 dapat mengalihkan isu persalinan kembali ke praktik-praktik tradisional.

....Praktik aborsi itu, lanjut Didik, terbongkar setelah polisi mendapat informasi dari masyarakat yang curiga dengan perut Narsi yang tiba-tiba mengecil.

(Kompas.com dengan judul «Terlibat Kasus Aborsi, Seorang Bidan di Kupang Ditangkap)

Kejadian dugaan malpraktik sendiri dituturkan oleh ibu $R, N u$ (54) yang langsung mendampingi putrinya saat proses kelahiran Jumat (22/7/2016) malam menceritakan, ia bersama bidan kampung (dukun beranak) dan turut mendampingi $R$ serta juga bidan TD dan anak buahnya saat upaya proses kelahiran di tempat praktik bidan TD di Mempawah.

(http://pontianak.tribunnews.com/2016/07/26/ breaking-news-detik-detik-rina-akan-melahirkandan-ditangani-bidan)
Sa bercerita, pada Jumat (15/6) pukul $23.00 \mathrm{WIB}$, istrinya mengalami kontraksi. Sejam kemudian bayinya langsung keluar. ...

(- detikNews: Pilu Warga Banten Kehilangan Istri yang Melahirkan di Malam Lebaran)

Informan yang didapatkan dalam berita:

\section{Masyarakat pada kasus 1}

Masyarakat yang mencurigai perubahan fisik NN melaporkan kondisi tersebut ke polisi. Masyarakat memahami aborsi sebagai tindakan ilegal. Kecurigaan ada praktik aborsi memicu pelaporan kasus tersebut kepada polisi. Model partisipasi ini dapat diadopsi untuk menggalang kepedulian terhadap perempuan. Perhatian terhadap ibu hamil dan bersalin, disosialisasikan dengan cara memberikan informasi hal-hal sederhana yang mudah dipahami masyarakat. Aborsi memiliki sisi kemanusiaan dan hukum. Laporan masyarakat ke polisi tentang kasus aborsi, menunjukkan pemahaman mereka ke arah persoalan hukum. Kasus ini membuktikan bahwa pemahaman satu aspek dalam pelayanan kehamilan dan persalinan dapat memicu kepedulian masyarakat kepada ibu hamil dan bersalin.

\section{Keluarga pada kasus 2}

Keluarga menceritakan kepada wartawan karena terjadi kematian, kesakitan, dan kehilangan harta benda. Penjelasan menggunakan prinsip untung rugi, lebih sesuai dilakukan terhadap klien yang berasal dari kelompok miskin dan berpendidikan rendah. Kasus ini menjadi contoh bagaimana sebaiknya tenaga kesehatan memberikan informasi dalam satu komunitas masyarakat yang miskin dan berpendidikan rendah, untuk mendukung pelayanan yang lebih manusiawi bagi perempuan. Pertimbangan finansial menjadi alasan utama bagi keluarga untuk mengabaikan keselamatan R.

\section{Keluarga pada kasus 3}

Suami klien menceritakan kronologi kejadian yang dialami istrinya. Kejadian kematian yang tidak wajar atau berkaitan dengan perkara pelayanan kesehatan dapat menjadi perhatian publik. Suami klien mengetahui bahwa perdarahan dapat membahayakan keselamatan istrinya, sehingga diperlukan kehadiran bidan sebagai profesi spesialistik untuk kehamilan dan persalinan yang terdekat saat itu. 


\section{Pembahasan \\ Peran Profesi}

Hubungan bidan dengan ibu tidak hanya sebatas isu klinis. Bidan adalah perempuan yang bekerja dalam lingkup sosial perempuan. Kedekatan bidan dengan klien telah dibentuk dalam kurun waktu hampir 30 tahun sejak dicetuskan program bidan desa, memunculkan hubungan pertemanan (friendship) sesama perempuan. Situasi ini sebenarnya menjadi modal utama bagi bidan, untuk melakukan pendekatan pelayanan kesehatan maternal berbasis hak asasi dan kemanusiaan melibatkan masyarakat. Isu-isu kemanusiaan dalam pelayanan kesehatan maternal yang mudah dipahami perlu diinformasikan terus menerus secara berulang, untuk menimbulkan reaksi spontan dari masyarakat untuk melindungi hak perempuan. Praktik-praktik yang mengabaikan keselamatan teman (klien) atas pertimbangan keuntungan pribadi, pelanggaran etika profesi, tindakan diluar kewenangan, perlu menjadi bahan diskusi dalam pertemuan rutin bidan. Jajaran pimpinan organisasi profesi bidan harus dapat mengabaikan kekhawatiran hilangnya keharmonisan hubungan diantara mereka akibat pembahasan tentang pelanggaran hak asasi dan kemanusiaan yang dilakukan oleh salah satu anggota. Pembahasan tentang pelayanan yang lebih manusiawi perlu diutamakan dibandingkan isu klinis dan prosedural. Audit maternal seharusnya menyertakan pembahasan isu kemanusiaan dan hak asasi dalam kejadian kesakitan dan kematian ibu. Sisi kemanusiaan yang terabaikan akibat perilaku bidan pada suatu kasus morbiditas dan mortalitas perlu diungkap untuk mendapatkan gambaran utuh suatu kejadian, tidak hanya berdasar aspek prosedural. Organisasi profesi perlu secara bersama-sama dan terus-menerus membuat kesepakatan bersama tentang pelayanan kesehatan ibu yang manusiawi ${ }^{24}$

Isu-isu sosial dan dukungan masyarakat terhadap perempuan hamil perlu menjadi bahan diskusi dalam kegiatan pendidikan bidan berkelanjutan. Fokus utama kegiatan pendidikan bidan berkelanjutan tidak hanya tentang standar pelayanan, kompetensi, dan prosedur, melainkan tentang menerapkan konsep kemanusiaan dan hak asasi dalam praktik sehari-hari ${ }^{25,12,26}$ Diskusi kelompok kecil bidan tentang pelayanan kebidanan berbasis kemanusiaan, dapat memanfaatkan kasus- kasus malpraktik bidan yang dimuat di media online. Bidan perlu belajar dari kasus-kasus tersebut, agar dapat memilih informasi yang tepat untuk membangkitkan rasa kemanusiaan masyarakat terhadap perempuan. Dukungan masyarakat dan keluarga terhadap perempuan adalah modal positif untuk membentuk pelayanan kesehatan maternal yang lebih manusiawi. ${ }^{27,28}$ Pembahasan tentang isu etikolegal, situasi sosial yang melatarbelakangi kejadian pelanggaran kemanusiaan, serta membentuk dukungan masyarakat terhadap ibu hamil di lingkungan mereka sebaiknya dilakukan oleh bidan bersama ahli kesehatan masyarakat dan ahli ilmu sosial. Kajian kasus rutin dalam organisasi profesi melibatkan ahli-ahli dari displin ilmu lain, dapat membuka wawasan tentang kehidupan sosial perempuan.

\section{Peran Pendidikan Bidan}

Belajar isu kemanusiaan dan hak asasi seharusnya dimulai sejak masa pendidikan, dilanjutkan selama para bidan tersebut masih melakukan praktik kebidanan. ${ }^{29,30}$ Perilaku profesional bidan yang mencakup baik persoalan teknis maupun persoalan social vulnerability dari pasien mereka di masa akan datang, memerlukan pendekatan berbasis kemanusiaan dan hak asasi. Administrator pendidikan bidan berperan strategis sebagai perancang kurikulum pembelajaran bidan yang menggunakan pendekatan kemanusiaan dan hak asasi. Mahasiswa kebidanan sejak tahun pertama masa pendidikan sebaiknya mulai dikenalkan dengan kasus-kasus kemanusiaan dan hak asasi dalam pelayanan bidan. Kuliah di luar kelas bertujuan mengenalkan isu sosial dalam kehidupan ibu hamil, sebaiknya dilakukan sejak tahun pertama pendidikan.

\section{Kesimpulan}

Kepercayaan sosial dan ketergantungan penuh wanita pada bidan menjadi suatu kondisi yang dapat berkontribusi dalam pengabaian hak asasi manusia dan keselamatan dalam proses pencarian dan pertolongan persalinan, tindakan di luar otoritas profesional, dan pencarian keuntungan dalam praktik pribadi petugas kesehatan. Pekerja profesional dan pendidik dalam kesehatan maternal dan kebidanan harus menemukan cara untuk 
memasukkan penerapan hak asasi manusia dalam praktik kebidanan berdasarkan kasus-kasus dari berita online dalam pertemuan continuing education dan seminar berkala asosiasi profesional, serta dalam kurikulum pendidikan kebidanan. Tindakan ini akan membantu mencegah dampak buruk dari pengabaian hak asasi dan konsekuensinya yang buruk pada ibu-ibu bersalin di masa depan.

\section{Daftar Rujukan}

1. Van Lerberghe W, Matthews Z, Achadi E, Ancona C, Campbell J, Channon A, et al. Country experience with strengthening of health systems and deployment of midwives in countries with high maternal mortality. Lancet. 2014 Sep 27;384(9949):1215-25.

2. Shankar A, Sebayang S, Guarenti L, Utomo B, Islam M, Fauveau V, et al. The village-based midwife programme in Indonesia. Lancet. 2008 Apr 12;371(9620):1226-9.

3. Shrestha $R$. The village midwife program and infant mortality in Indonesia. Bull Indones Econ Stud. 2010;46(2):193-211.

4. Heywood P, Harahap NP, Aryani S. Recent changes in human resources for health and health facilities at the district level in Indonesia: evidence from 3 districts in Java. Hum Resour Health. 2011 Feb 13;9:5.

5. Cronk M. The Midwife: A Professional Servant? In: The Midwife-Mother Relationship. 2010. p. $55-65$.

6. Kirkham M, Stapleton H. Midwives' support needs as childbirth changes. J Adv Nurs. 2000;32(2):465-72.

7. Kabakian-Khasholian T, Campbell O, ShediacRizkallah M, Ghorayeb F. Women's experiences of maternity care: satisfaction or passivity? Soc Sci Med. 2000;51(1):103-13.

8. Jewkes R, Abrahams N, Mvo Z. Why do nurses abuse patients? Reflections from South African obstetric services. Soc Sci Med. 1998;47(11):1781-95.

9. d'Oliveira AFPL, Ana Flávia Pires, Diniz SG, Schraiber LB. Violence against women in health-care institutions: an emerging problem. Lancet. 2002;359(9318):1681-5.

10. Kruger L, Schoombee C. The other side of caring: abuse in a South African maternity ward.
J Reprod Infant Psychol. 2009;28(1):84-101.

11. Hardee K, Gay J, Blanc AK. Maternal morbidity: neglected dimension of safe motherhood in the developing world. Glob Public Health. 2012 Mar 16;7(6):603-17.

12. Gruskin S, Ahmed S, Bogecho D, Ferguson L, Hanefeld J, Maccarthy S, et al. Human rights in health systems frameworks: what is there, what is missing and why does it matter? Glob Public Health. 2012 Jan 23;7(4):337-51.

13. Rosen HE, Lynam PF, Carr C, Reis V, Ricca J, Bazant ES, et al. Direct observation of respectful maternity care in five countries: a cross-sectional study of health facilities in East and Southern Africa. BMC Pregnancy Childbirth. 2015 Nov 23;15:306.

14. Ndwiga C, Warren CE, Ritter J, Sripad P, Abuya T. Exploring provider perspectives on respectful maternity care in Kenya: "Work with what you have.” Reprod Health. 2017 Aug 22;14(1):99.

15. Moyer CA, Adongo PB, Aborigo RA, Hodgson A, Engmann CM. "They treat you like you are not a human being": maltreatment during labour and delivery in rural northern Ghana. Midwifery. 2014 Feb;30(2):262-8.

16. Eliasson M, Kainz G, von Post I. Uncaring Midwives. Nurs Ethics. 2008;15(4):500-11.

17. Bowler IM. Stereotypes of women of Asian descent in midwifery: some evidence. Midwifery. 1993 Mar;9(1):7-16.

18. Bowler I. "They"re not the same as us': midwives' stereotypes of South Asian descent maternity patients. Sociol Health Illn. 1993;15(2):157-78.

19. Bowes AM, Meehan Domokos T. Pakistani women and maternity care: raising muted voices. Sociol Health Illn. 1996;18(1):45-65.

20. Kirkham M, Stapleton H, Curtis P, Thomas G. Stereotyping as a professional defence mechanism. British Journal of Midwifery. 2002;10(9):549-52.

21. Bohren MA, Vogel JP, Hunter EC, Lutsiv O, Makh SK, Souza JP, et al. The Mistreatment of Women during Childbirth in Health Facilities Globally: A Mixed-Methods Systematic Review. PLoS Med. 2015 Jun;12(6):e1001847; discussion e1001847.

22. Andajani-Sutjahjo S, Manderson L. Stillbirth, Neonatal Death and Reproductive Rights 
in Indonesia. Reprod Health Matters. 2004;12(24):181-8.

23. Rominski SD, Manu A, Maya E, Morhe ESK, Dalton VK. Discontinuation of long-acting reversible contraception versus short-term hormonal methods in urban Ghana: A pilot longitudinal study. Int J Gynaecol Obstet. 2018 Aug;142(2):235-6.

24. Sulaeman ES, Murti B, Waryana W. Peran Kepemimpinan, Modal Sosial, Akses Informasi serta Petugas dan Fasilitator Kesehatan dalam Pemberdayaan Masyarakat Bidang Kesehatan. Kesmas: National Public Health Journal. 2015;9(4):353.

25. D'Ambruoso L, Byass P, Qomariyah SN. Can the right to health inform public health planning in developing counties? A case study for maternal healthcare from Indonesia. Glob Health Action. 2008;1(1):1828.

26. Freedman LP. Using human rights in maternal mortality programs: from analysis to strategy.
Int J Gynaecol Obstet. 2001 Oct;75(1):51-60; discussion 61.

27. Fathalla MF. The Reproductive Health Community: A Valuable Asset for Achieving the MDGs. Stud Fam Plann. 2005;36(2):135-7.

28. Kasamba N, Kaye DK, Mbalinda SN. Community awareness about risk factors, presentation and prevention and obstetric fistula in Nabitovu village, Iganga district, Uganda. BMC Pregnancy Childbirth. 2013 Dec 10;13:229.

29. Armstrong N. Role modelling in the clinical workplace. British Journal of Midwifery. 2008;16(9):596-601.

30. Yanti Y, Claramita M, Emilia O, Hakimi M. Students' understanding of "Women-Centred Care Philosophy" in midwifery care through Continuity of Care $(\mathrm{CoC})$ learning model: a quasi-experimental study. BMC Nurs [Internet]. 2015;14(1). Available from: http://dx.doi. org/10.1186/s12912-015-0072-z 